Article

\title{
Energy Coupling of Laser Radiation on AISI 304 Stainless Steel: Effect of High Temperatures and Surface Oxidation
}

\author{
Dominik Hipp ${ }^{1, *(\mathbb{D})}$, Achim Mahrle ${ }^{2}$ (I) and Eckhard Beyer ${ }^{1}$ \\ 1 Institute of Manufacturing Science and Engineering, TU Dresden, PO Box, D-01062 Dresden, Germany \\ 2 Fraunhofer IWS Dresden, Winterbergstraße 28, D-01277 Dresden, Germany \\ * Correspondence: dominik.hipp@tu-dresden.de
}

Received: 13 August 2019; Accepted: 29 August 2019; Published: 30 August 2019

\begin{abstract}
The industrial application of laser materials processing methods is still far ahead of research into the physical phenomena occurring during these processes. In particular, the effect of high temperatures on the energy coupling of laser irradiation of metals is poorly understood. However, most processes in laser materials treatment involve temperatures above the melting point or even cause evaporation. This study therefore evaluates the effect of high temperatures on the energy coupling efficiency of stainless steel experimentally for three typical laser wavelengths $(515 \mathrm{~nm}$, $1.07 \mu \mathrm{m}, 10.6 \mu \mathrm{m})$. As a result, it is shown that the effect of temperature on the energy coupling efficiency depends on the wavelength. In this context the relevance of the X-point phenomenon known from the emissivity theory could be demonstrated for laser material processing. Further, the effect of a process-induced surface oxidation is analyzed. At temperatures above $650{ }^{\circ} \mathrm{C}$ the energy coupling efficiency dramatically increases to around $65 \%$ at melting point and stays at this high level even in the liquid phase.
\end{abstract}

Keywords: energy coupling efficiency; high temperatures; laser material processing; surface oxidation; absorptivity

\section{Introduction}

Nowadays laser materials processing is well-established in industry for several applications such as welding, cutting, cladding, etc. These processes mostly involve temperatures above the melting point and can even reach the boiling point. However, the effect of higher temperatures on the energy coupling of laser radiation is still scarcely explored. Tabulated values of optical properties such as refractive index $n$ and extinction coefficient $k$ in standard textbooks [1-3] are reported for room temperature or for particular measuring conditions far below room temperature. In addition, the absorptivity calculated from the Fresnel equations using these optical properties is only valid for perfect smooth surfaces. Some studies tried to examine the effect of non-laboratory conditions on the energy coupling of laser radiation. While for the effect of surface roughness, both theoretical calculation models [4-6] and experimental results $[7,8]$ were published, but the results for the temperature dependence are only sparse. Using Kirchhoff's law of thermal radiation, which states that under the assumption of a thermodynamic equilibrium the direct spectral emissivity corresponds to the direct spectral absorptivity, results on the temperature dependence of the emissivity can be considered instead. Price [9] ascertained for the emissivity, that the effect of temperature depends on the emitted wavelength of the light. He found, that there is a specific wavelength for each material at which the emissivity is completely independent of the temperature. This wavelength was termed the X-point. At wavelengths above this X-point, the emissivity increases with the temperature while it decreases below. For iron and platinum, the X-point 
was later found around $2 \mu \mathrm{m}$ [10] and for aluminum at $0.95 \mu \mathrm{m}$ [11]. In addition, the X-point was observed in several experiments regarding the temperature dependence of the absorptivity without relating to this phenomenon $[8,12,13]$. However, one has to distinguish at this point between the absorptivity and the energy coupling efficiency. While the absorptivity is an intrinsic material property, which applies for ideal surfaces and a specific temperature, the energy coupling efficiency is an integral value considering phenomena like multiple reflections due to surface roughness or surface defects on the one hand and a temperature range as a result of the coupled light energy on the other. Therefore, for laser material processing where technical surfaces and temperature ranges from room temperature to melting point are common, the energy coupling efficiency is crucial while the absorptivity only plays a minor role. The afore mentioned X-point is thereby only validated for the influence on the emissivity/absorptivity, the question as to if this phenomenon affects the integral coupling efficiency and consequently has to be considered during laser materials processing is still open. Further, there are contradictory results concerning the energy coupling at temperatures around the phase change of the material. While some studies observed a decrease of the energy coupling efficiency during the $\mathrm{CO}_{2}$-laser irradiation of aluminum at higher temperatures [8,14], others report a sudden increase after reaching the liquid phase [15-17]. The decrease was explained by possibly structural changes possibly occurring in the probe [14]. A last effect, which is thought to have an influence on the energy coupling efficiency during a real process is the induced surface oxidation. Some studies reported higher values of energy coupling on oxidized surfaces [18-20]. Contradictorily, others observed an initial decrease of the coupling efficiency while the effect of oxidation, in turn resulting in higher coupling efficiencies, only takes place above a certain temperature range [21-23]. The decreasing coupling efficiency was ruled as due to a cleaning effect of the surface due to the laser irradiation. In [24] the increase in coupling efficiency for stainless steel started above $600{ }^{\circ} \mathrm{C}$.

As one can see, the results in literature contradict themselves in several points. However, the exact knowledge of all the occurring effects is a crucial necessity to understand the processes and therefore be able to optimize them. This study tries to fill this gap by experimentally determining the energy coupling efficiency in dependence on the wavelength, temperature and oxidation state. AISI 304 stainless steel is irradiated with three different laser wavelengths $(10.6 \mu \mathrm{m}, 1.07 \mu \mathrm{m}, 0.515 \mu \mathrm{m})$ in inert-gas atmosphere as well as for a wavelength of $1.07 \mu \mathrm{m}$ in an active gas atmosphere. Thus, the X-point phenomenon can be examined and the relevance for laser materials processing can be assessed. In conclusion, the results of this study will provide a knowledge foundation, which will advance our understanding of laser materials processing.

The paper is structured as follows. In Section 2 the measuring method is described as well as the investigated samples are characterized. In Section 3 the experimental results on the temperature dependence and the effect of oxidation are presented and discussed. Section 4 summarizes the results and draws some conclusions.

\section{Materials and Methods}

Since existing methods for the determination of the absorptivity (e.g., integrated sphere [25] or calorimetry [4]) mostly have shortcomings when it comes to the estimation of the energy coupling at high temperatures, a new measuring technique was developed. This new method is able to determine the coupling efficiency and also to link the results to the process temperature. It consists of two steps. First, the temperature-time curve of the probe irradiation and the subsequent cooling regime was assessed. The energy coupling efficiency was then determined in a second step through the alignment of the experimental temperature-time curves with a heat flow computation. The experimental setup is schematically illustrated in Figure 1 and consisted of a sample holder which thermally isolated the disk-shaped probe at the contact face. The probe was irradiated centrically with a stationary laser beam; the temperature increase of the probe was captured from underneath using a thermographic setup. This allowed to visualize the heat distribution inside the probe, which had to be considered for a high measuring accuracy [26]. For the temperature measurement the emissivity was determined in 
oven experiments beforehand. The probes were irradiated for $5 \mathrm{~s}$; the temperature signal was recorded for $15 \mathrm{~s}$ to also capture the cooling regime.

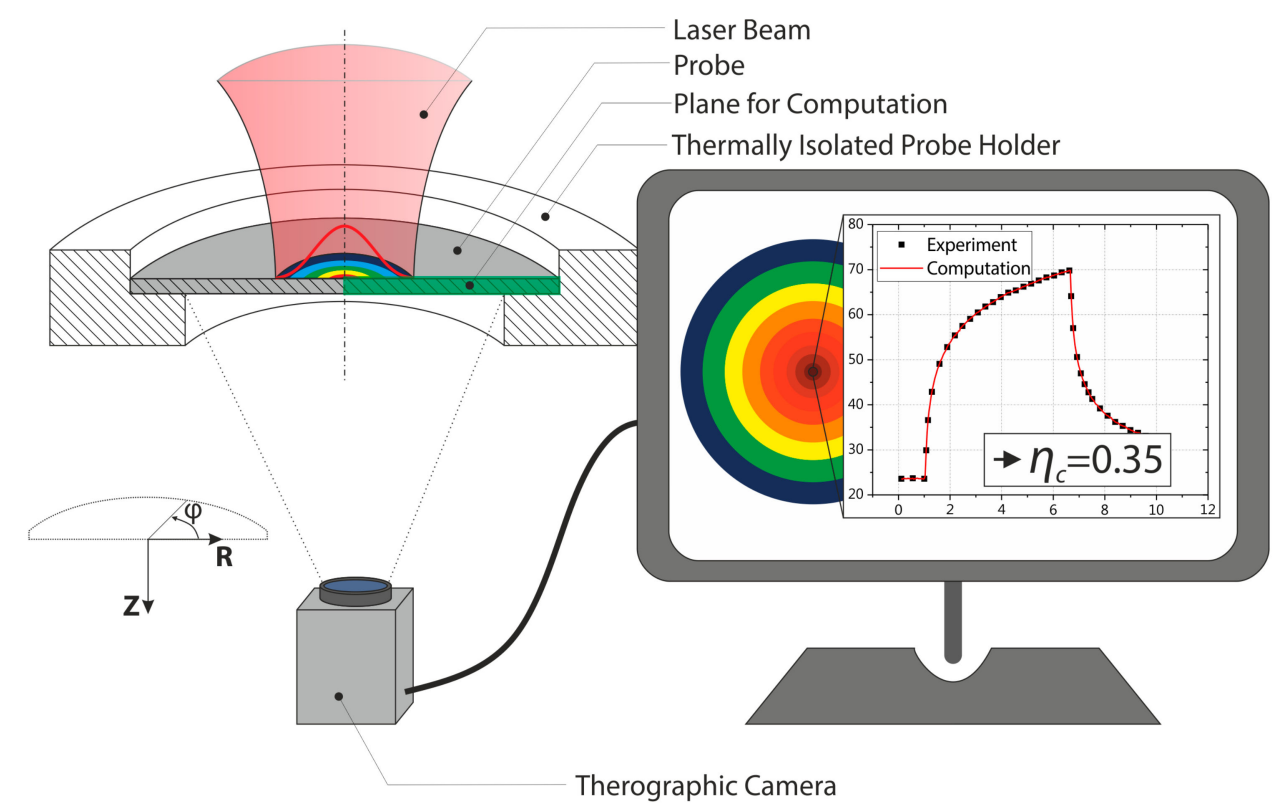

Figure 1. Drawing of the determination method of the temperature dependent coupling efficiency.

In the second step, a theoretical temperature-time curve was calculated through a heat flow computation. The experimental setup was designed in a axisymmetric way so that the computation model could be reduced to a $2 \mathrm{D}$ problem. Therefore, the temperature distribution was calculated as the solution of the following model equation in cylindrical coordinates $R$ and $Z$ :

$$
\frac{\partial \vartheta}{\partial t}=\frac{1}{\rho c_{\rho}(\vartheta)} \times\left[\frac{1}{R} \frac{\partial}{\partial R}\left[R \times \lambda_{t h}[\vartheta] \frac{\partial \vartheta}{\partial R}\right]+\frac{\partial}{\partial Z}\left[\lambda_{t h}[\vartheta] \frac{\partial \vartheta}{\partial Z}\right]\right]
$$

With $\rho$ the density, $c_{\rho}(\vartheta)$ the temperature dependent specific heat capacity and $\lambda_{t h}(\vartheta)$ the temperature dependent thermal conductivity. Material data were extracted from the database "Total Materia" [27] and are listed in Table A1. The heat flux of the laser beam $\dot{q}_{L}$ as well as the heat losses through convection $\dot{q}_{C}$ and thermal radiation $\dot{q}_{R}$ were considered as a boundary condition at the top face of the probe $\left(Z=z_{\text {top }}\right)$ :

$$
\left.\lambda \frac{\partial \vartheta}{\partial Z}\right|_{Z=z_{\text {top }}}=\dot{q}_{L}-\dot{q}_{C}-\dot{q}_{R}=\frac{2 \eta_{c} P_{L}}{\pi R_{0}^{2}} \times \exp \left(-\frac{2 \times R^{2}}{R_{0}^{2}}\right)-h_{t}\left(\vartheta-\vartheta_{0}\right)-\varepsilon_{E} \sigma_{B}\left(T^{4}-T_{0}^{4}\right)
$$

with $\eta_{c}$ the coupling efficiency, $P_{L}$ the applied laser power, $R_{0}$ the laser beam radius at the top face of the probe, $h_{t}$ the heat transfer coefficient, $\varepsilon_{E}$ the emissivity and $\sigma_{B}$ the Stefan-Boltzmann constant. The model equations were numerically solved and provided as the result of the computation a theoretical temperature-time curve for the irradiation. It could be shown in a sensitivity analysis (see [28] for details) that the theoretical temperature-time curve only coincides with the experimental curve for one specific value of the energy coupling efficiency. Therefore the model was suited to inversely calculate the energy coupling efficiency. As a further result of the heat flow model, the energy coupling efficiency could be ascribed to the temperatures in the direct interaction zone between laser beam and material during the experiments. This allows the link between the measured coupling efficiency and the prevailing temperature and therefore allows the determination of the temperature dependence of the coupling efficiency. 
The experiments were conducted on AISI 304 stainless steel $\left(\mathrm{X}_{5} \mathrm{CrNi}_{18-10}\right)$ probes of $60 \mathrm{~mm}$ in diameter and $3 \mathrm{~mm}$ in thickness. The surface was polished (root mean square surface roughness as deviation from surface normal $R_{r m s}=0.016 \mu \mathrm{m}$; spacing between surface roughness profiles $a=2.91 \mu \mathrm{m}$ ) to reduce the effect of surface roughness. Three different $\mathrm{CW}$ lasers sources were used: $\mathrm{CO}_{2}$-laser (ROFIN-SINAR Laser GmbH, Hamburg, Germany), a fiber laser (IPG Laser GmbH, Burbach, Germany) and a frequency-doubled disk laser (TRUMPF GmbH + Co. KG, Ditzingen, Germany) with wavelengths of $10.6 \mu \mathrm{m}, 1.07 \mu \mathrm{m}$ and $515 \mathrm{~nm}$, respectively. The process temperature was varied through different optical setups and laser powers (for details see Table A2). The experiments for the evaluation of the temperature dependence were conducted in an argon atmosphere (see inert gas cabin in Figure 2) with a residual oxygen content below $5 \mathrm{ppm}$. The effect of oxidation was studied for fiber laser irradiation $(\lambda=1.07 \mu \mathrm{m})$ in normal atmosphere. The final experimental setup is depicted in Figure 2 . The protective glass was adjusted for the three used wavelengths.

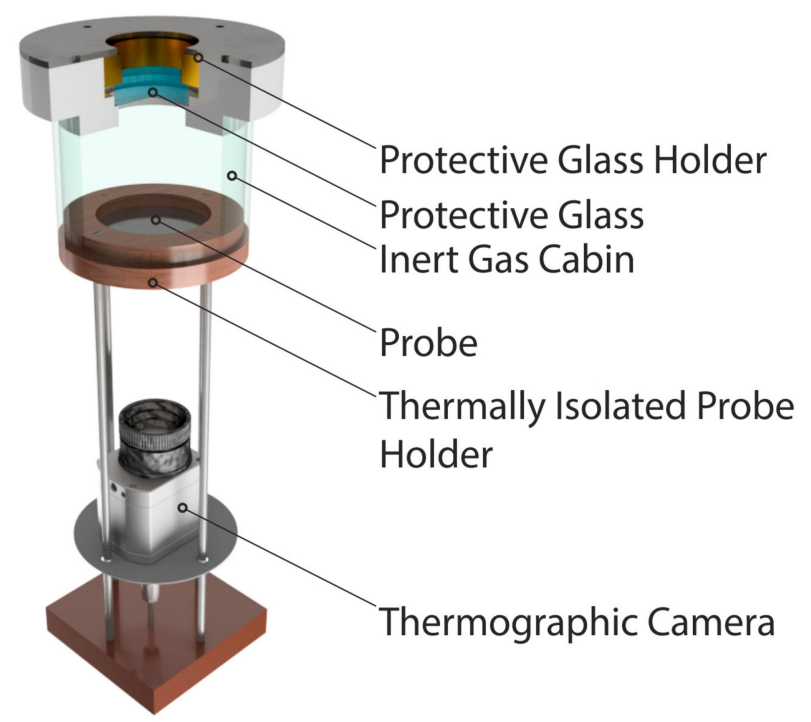

Figure 2. Setup for the determination of the temperature dependent energy coupling efficiency under the usage of a thermographic camera.

\section{Results and Discussion}

For the evaluation of the energy coupling efficiency, an alignment between experimental and theoretical temperature-time curves is needed. In Figure 3 this is exemplarily demonstrated for one trial run. In can be seen that the fit between experiment and computation is good for both the complete time range and all eight evaluated measuring positions. The deviations at the measuring positions 7 and 8 only evaluate to $2 \mathrm{~K}$ and can be neglected. Therefore it can be concluded, that the theoretical model computes the temperature distribution in good agreement to the experiment and can be used to inversely calculate the energy coupling efficiency on the one hand, and the maximum temperature increase through the laser irradiation on the other. Since the temperature drop after turning off the laser at $5 \mathrm{~s}$ is mainly influenced by heat conduction inside the probe, the material properties needed for the computation also seem to correspond with the real ones, resulting in a good alignment. 

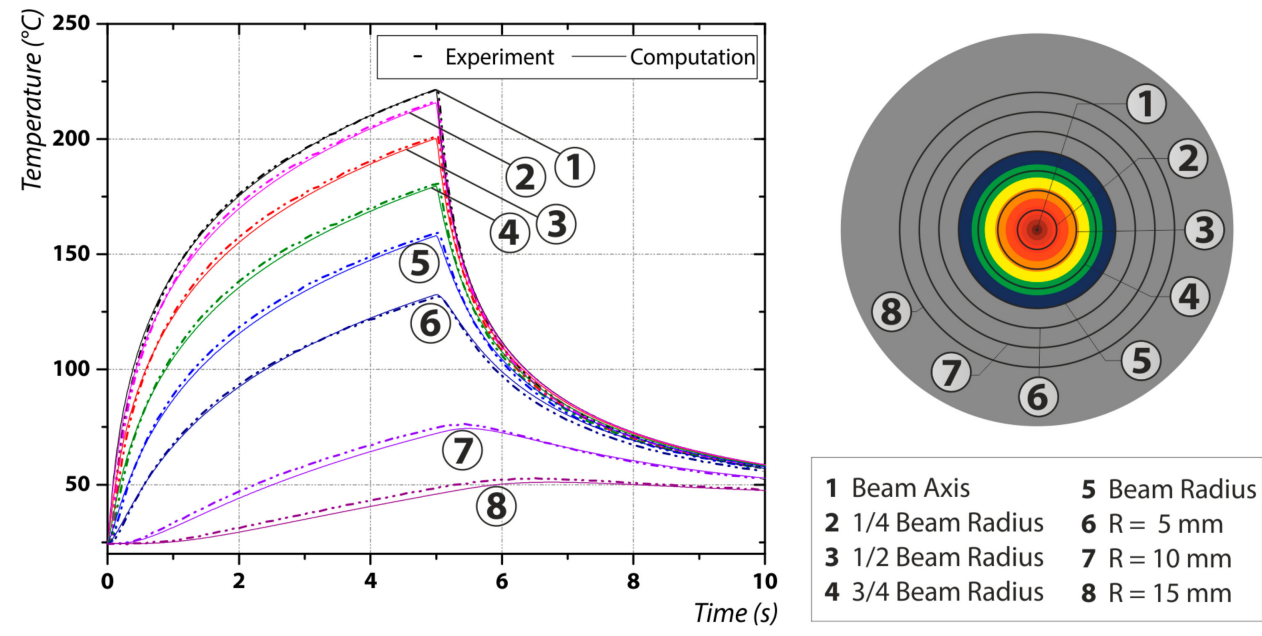

Figure 3. The fit between the computational and experimental temperature-time curves (left) at different measuring locations (right).

\subsection{Temperature Dependence}

The results for the measurement of the temperature dependent coupling efficiency are illustrated in Figure 4. It is obvious that there are different tendencies observable. The energy coupling efficiency of the frequency doubled disk laser (green line) with a wavelength of $0.515 \mu \mathrm{m}$ monotonically decreases almost linearly with temperature. Also at temperatures above phase change and therefore in the liquid phase the energy coupling efficiency decreases slightly. The decline from $\eta_{c}=0.334$ at $200{ }^{\circ} \mathrm{C}$ to $\eta_{c}=0.291$ in the liquid phase evaluates to around $13 \%$.

The energy coupling efficiency for laser radiation with $1.07 \mu \mathrm{m}$ wavelength shows a similar behavior at higher temperatures. While below approximately $1000{ }^{\circ} \mathrm{C}$ the coupling efficiency is independent of the temperature, above this temperature a slight decrease of efficiency was measured. The temperature independent energy coupling efficiency is in good agreement with the results for the absorptivity at temperatures below $600{ }^{\circ} \mathrm{C}$ in [24]. As mentioned before, the decrease of the absorptivity below the melting point was attributed to a cleaning effect of the surface [21]. In our experiments we believe that a cleaning effect can be excluded for two reasons. First, we used cold rolled probes which were pickled to remove any possibly existing oxidation layer in consequence of the mechanical treatment. The probes were further polished and then cleaned in a ultrasonic ethanol bath. Second, the decrease also continues above the melting point, which contradicts the observations for aluminum [21-23]. Therefore, we believe that the measured drop in energy coupling is caused by the temperature increase only.

Interestingly, the energy coupling efficiency of the frequency doubled disk laser $(\lambda=0.515 \mu \mathrm{m})$ and the fiber laser $(\lambda=1.07 \mu \mathrm{m})$ approximate each other in the liquid phase (Figure 4$)$. Since the energy coupling for light in the visible wavelength spectra is believed to be dominated by interband absorption [29], the measured approach in the liquid phase can be an indication for the theory that in the liquid phase interband absorption is absent [30,31]. Therefore, the believed increased energy coupling efficiency at room temperature for smaller wavelengths $[32,33]$ can diminish in the liquid phase through this effect. 


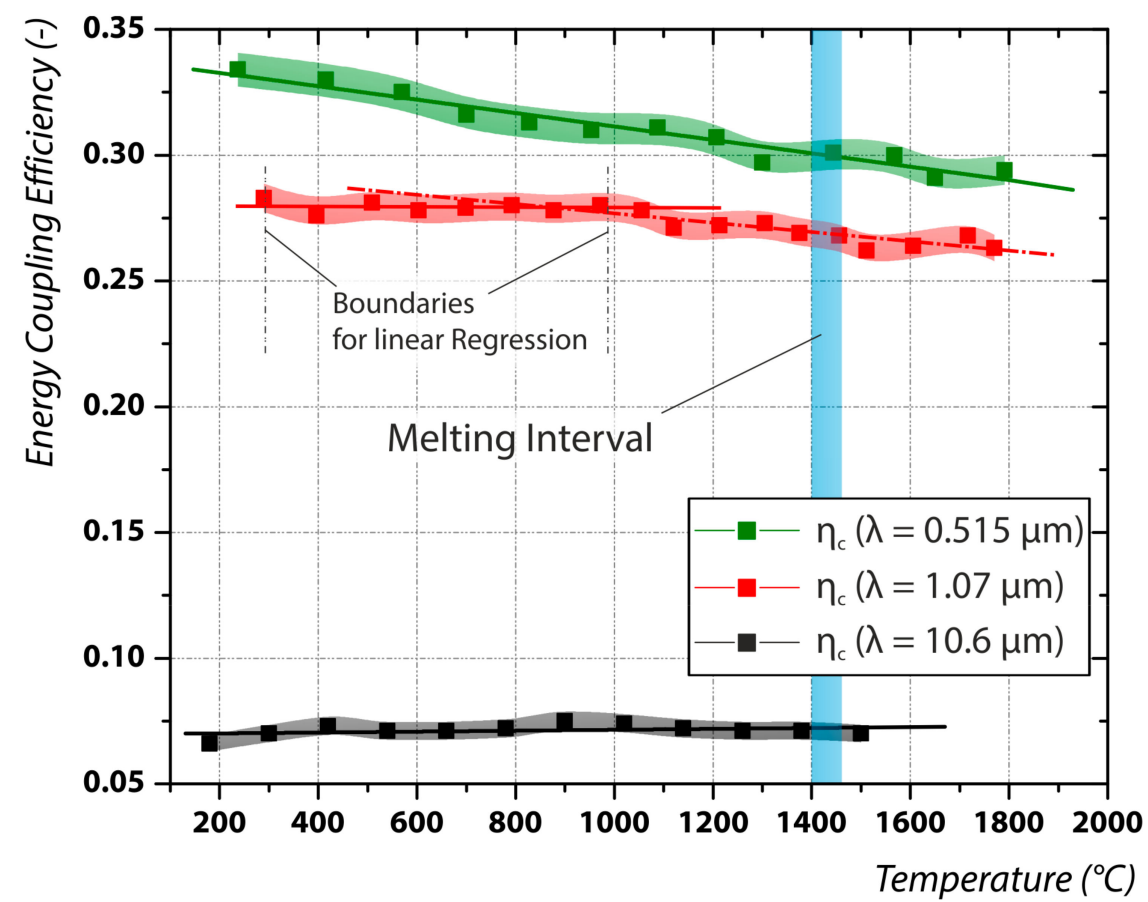

Figure 4. Results for the temperature dependent energy coupling efficiency for the three wavelengths $(0.515,1.07$, and $10.6 \mu \mathrm{m})$.

Also, since the energy coupling for both wavelengths $(0.515 \mu \mathrm{m}, 1.07 \mu \mathrm{m})$ shows a negative temperature coefficient, this indicates that the X-point for 304 stainless steel is located in the mid-infrared. The results for the energy coupling efficiency for $\mathrm{CO}_{2}$-laser radiation also confirm this hypothesis. For a wavelength of $10.6 \mu \mathrm{m}$ the energy coupling efficiency is completely independent of the underlying process temperature. The measured trend in our experiments is identical compared to results in the literature [24], however, our values are lower. This can be a consequence of the much smaller surface roughness [7] of our used probes.

Further, for all investigated wavelengths no sudden change of the coupling efficiency at the phase change was detected. Therefore, contradictory to literature, it can be stated that for polished stainless steel probes a phase change does not affect the energy coupling at all investigated wavelengths. Thus, the sudden change at the phase transition observed in the literature might be an effect of a surface smoothening occurring in the liquid phase [34], however, this thesis must be further investigated.

\subsection{Effect of Surface Oxidation}

In Figure 5 the measured coupling efficiency for fiber laser radiation $(\lambda=1.07 \mu \mathrm{m})$ in an oxidizing environment is compared to the one in an inert gas atmosphere. Below $600{ }^{\circ} \mathrm{C}$ the agreement between the two curves is good. Above around $650{ }^{\circ} \mathrm{C}$ the energy coupling efficiency in the oxidizing environment increases dramatically, reaching a value of $\eta_{c}=0.508$ at $1000{ }^{\circ} \mathrm{C}$ and $\eta_{c}=0.653$ in the liquid phase. Interestingly, the energy coupling efficiency below and above the phase transition are comparable, although the solidified melt pool clearly shows signs of a melt pool convection. One reason for this may be found in the high melting point of chromium-III-oxide $\left(2329^{\circ} \mathrm{C}\right)$, which is preferably formed during laser irradiation of stainless steel due to the high oxygen affinity of chromium [35]. Therefore it is believed, that the chromium-III-oxide is still in the solid phase and covers the melt pool. Chromium-III-oxide exhibits a high absorptivity of $81.9 \%$ [36], wherefore the measured energy coupling efficiency is high. However, it also exhibits a high attenuation length of $4400 \mathrm{~nm}$ and is thus partly transparent for the fiber laser radiation. The measured energy coupling efficiency is therefore believed to be a mix of the energy coupling of the oxide layer and of the base metal beneath. 


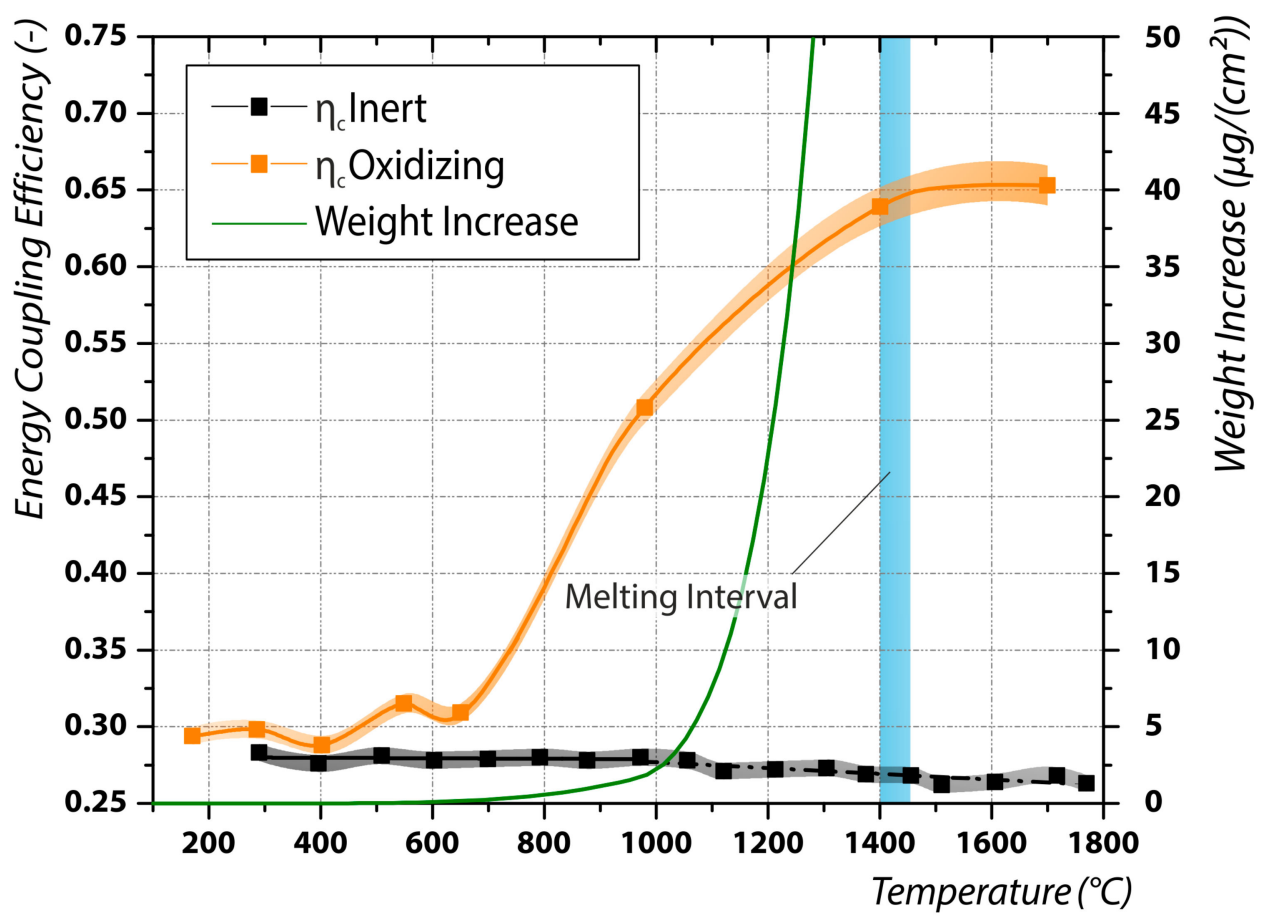

Figure 5. Results for the evaluation of the effect of a surface oxidation on the temperature dependent energy coupling efficiency for fiber laser radiation $(\lambda=1.07 \mu \mathrm{m})$.

By using data of [37] and applying these to the Arrhenius law and parabolic rate law, the weight increase through the oxidation can be theoretically calculated. This is also illustrated in Figure 5. It is obvious that the weight increase coincides with the increase in coupling efficiency at temperatures above $650{ }^{\circ} \mathrm{C}$. Therefore, the measured higher coupling efficiency can be directly related to the oxidation process. Further, by using these data, a temperature dependent oxide layer thickness can be calculated. At melting point this evaluates to around $600 \mathrm{~nm}$ in thickness. Using the Beer-Lambert law, the calculated attenuation of the laser irradiation by the oxide layer $\left(\mathrm{Cr}_{2} \mathrm{O}_{3}\right)$ is evaluated at the melting point to be $40 \%$. This is again an indication for the thesis above, that the measured energy coupling efficiency is a mix of the coupling in the oxide layer and in the base metal below.

The measured temperature threshold $\left(650{ }^{\circ} \mathrm{C}\right)$ for the increase in coupling efficiency as a consequence of a process-induced oxidation in Figure 5 is in good agreement with data provided in the literature [24]. However, we measured a steeper increase of the coupling efficiency. Further our experiments demonstrated that the increase continues up to the melting point and remains on this high level even in the liquid phase.

\section{Summary and Conclusions}

The knowledge of the physical phenomena impacting the energy coupling efficiency during laser material treatment is a fundamental necessity to assess, understand and optimize these processes. However, little is known about the effect of high temperatures as well as of a process-induced surface oxidation on the energy coupling of a laser beam in materials. This study experimentally evaluated the effects of high temperatures and of an oxidizing environment on the energy coupling efficiency on stainless steel. The following conclusions can be drawn:

The energy coupling mechanism of laser radiation at high temperatures depends on the wavelength. The energy coupling efficiency of visible laser irradiation $(\lambda=0.515 \mu \mathrm{m})$ shows an approximately linear decrease with temperature.

The energy coupling efficiency for laser irradiation in the near infrared $(\lambda=1.07 \mu \mathrm{m})$ is below $1000^{\circ} \mathrm{C}$ independent of the temperature, above a linear decrease was measured with temperature. 
The energy coupling efficiency for $\mathrm{CO}_{2}$ laser irradiation $(\lambda=10.6 \mu \mathrm{m})$ is completely independent of the temperature for the evaluated temperature range.

The process-induced oxidation leads to a dramatic increase of the energy coupling efficiency above $650^{\circ} \mathrm{C}$ and stays at this high level also in the liquid phase.

The experimental results are of special interest for the process understanding in the field of laser material processing. It could be shown that the X-point phenomenon known from emissivity and absorptivity theory also influences the integral value of the energy coupling efficiency. Thus, the relevance of the X-point for laser material processing could be demonstrated. As a result, the advantage of increased energy coupling at room temperature for laser wavelengths in the visible range compared to near infrared diminishes in the liquid phase for the evaluated stainless steel.

Author Contributions: The research was conceptualized by A.M. and D.H., the method was developed by A.M and D.H., the experiments were conducted by D.H., the results were discussed by A.M., D.H. and E.B., The manuscript was written and reviewed by A.M. and D.H.

Acknowledgments: We acknowledge support of the SLUB/TU Dresden for publishing open access.

Conflicts of Interest: The authors declare no conflict of interest.

\section{Appendix A}

Table A1. Material data AISI 304.

\begin{tabular}{ccc}
\hline Density $\left(\mathrm{kg} / \mathrm{m}^{3}\right)$ & $293 \mathrm{~K}$ & 8030 \\
\hline Heat conductivity & $293 \mathrm{~K}$ & 14.8 \\
$(\mathrm{~W} /(\mathrm{mK}))$ & $400 \mathrm{~K}$ & 16.6 \\
& $500 \mathrm{~K}$ & 18.3 \\
& $600 \mathrm{~K}$ & 19.8 \\
& $700 \mathrm{~K}$ & 21.2 \\
& $800 \mathrm{~K}$ & 22.6 \\
& $900 \mathrm{~K}$ & 24 \\
& $1000 \mathrm{~K}$ & 25.4 \\
& $1100 \mathrm{~K}$ & 25.7 \\
\hline Heat capacity $(\mathrm{J} /(\mathrm{kg} \cdot \mathrm{K}))$ & $293 \mathrm{~K}$ & 500 \\
& $473 \mathrm{~K}$ & 510 \\
& $673 \mathrm{~K}$ & 550 \\
& $873 \mathrm{~K}$ & 585 \\
& $1073 \mathrm{~K}$ & 630 \\
\hline
\end{tabular}

Table A2. Laser beam data.

\begin{tabular}{cccc}
\hline Header & Wavelenth $\lambda(\mu \mathrm{m})$ & Beam Radius $(\mathbf{m m})$ & Laser Power $(\mathbf{W})$ \\
\hline Frequency-doubled disk laser & 0.515 & 3.68 & $0-1000$ \\
Fiber laser & 1.07 & 0.486 & $0-400$ \\
$\mathrm{CO}_{2}$ laser & 10.6 & 3 & $0-2400$ \\
\hline
\end{tabular}

\section{References}

1. Palik, E.D. Handbook of Optical Constants of Solids; Academic Press: Orlando, FL, USA, 1985.

2. Haynes, W.M.; Lide, D.R.; Bruno, T.J. CRC Handbook of Chemistry and Physics, 96th ed.; CRC Press: Boca Raton, FL, USA, 2015.

3. Weaver, J.H.; Krafka, C.; Lynch, D.W.; Koch, E.E. Optical Properties of Metals Pt. I: The Transition Metals; Fachinformationszentrum Energie Physik Mathematik GmbH: Karlsruhe, Germany, 1981.

4. Wang, H.; Kawahito, Y.; Yoshida, R.; Nakashima, Y.; Shiokawa, K. A Model to Calculate the Laser Absorption Property of Actual Surface. Int. J. Heat Mass Transf. 2018, 118, 562-569. [CrossRef] 
5. Bergström, D.; Powell, J.; Kaplan, A.F.H. The Absorption of Light by Rough Metal Surfaces - A ThreeDimensional Ray-Tracing Analysis. J. Appl. Phys. 2008, 103, 103515. [CrossRef]

6. Kaplan, A.F.H. Local Absorptivity Modulation of a $1 \mu \mathrm{m}$-Laser Beam Through Surface Waviness. Appl. Surf. Sci. 2012, 258, 9732-9736. [CrossRef]

7. Hipp, D.; Mahrle, A.; Beyer, E. Beyond Fresnel: Absorption of fibre laser radiation at rough stainless steel surfaces. J. Phys. D Appl. Phys. 2019, 52, 355302. [CrossRef]

8. Stern, G. Absorptivity of $\mathrm{CW} \mathrm{CO}_{2}, \mathrm{CO}$ and YAG-Laser Beams by Different Metallic Alloys. In Proceedings of 3rd European Conferfence on Laser Treamnet of Materials, AWT, Erlangen, Germany, 17-19 September 1990; Sprechsaal Publishing Group: Coburg, Germany, 1990; pp. 25-35.

9. Price, D.J. The Temperature Variation of the Emissivity of Metals in the Near Infra-Red. Proc. Phys. Soc. 1947, 59, 131-138. [CrossRef]

10. Seban, R.A. The Emissivity of Transition Metals in the Infrared. J. Heat Transf. 1965, 87, 173-176. [CrossRef]

11. Kalenskii, A.V.; Zvekov, A.A. Temperature Dependences of the Optical Properties of Aluminum Nanoparticles. Tech. Phys. Lett. 2017, 43, 535-538. [CrossRef]

12. Jones, M.C.; Palmer, D.C.; Tien, C.L. Infrared Absorptivities of Transition Metals at Room and Liquid-Helium Temperatures. J. Opt. Soc. Am. 1972, 62, 353-360. [CrossRef]

13. Ujihara, K. Reflectivity of Metals at High Temperatures. J Appl Phys 1972, 43, 2376-2383. [CrossRef]

14. Konov, V.I.; Tokarev, V.N. Temperature Dependence of the Absorptivity of Aluminum Targets at the $10.6 \mu \mathrm{m}$ Wavelength. Sov. J. Quantum Electron. 1983, 13, 177-180. [CrossRef]

15. Dreehsen, H.G.; Hartwich, C.; Schaefer, J.H.; Uhlenbusch, J. Measurement of the Optical Constants of Al Above the Melting Point at $\lambda=10.6 \mu \mathrm{m}$. J. Appl. Phys. 1984, 56, 238-240. [CrossRef]

16. Ursu, I.; Mihailescu, I.N.; Apostol, I.; Dinescu, M.; Hening, A.; Stoica, M.; Prokhorov, A.M.; Ageev, V.P.; Konov, V.I.; Tokarev, V.N. On the Behaviour of Aluminium under Microsecond Pulsed TEA $\mathrm{CO}_{2}$ Laser Radiation in Vacuum. J Phys D Appl Phys. 1984, 17, 1315-1324. [CrossRef]

17. Brückner, M.; Schäfer, J.H.; Uhlenbusch, J. Ellipsometric Measurement of the Optical Constants of Solid and Molten Aluminum and Copper at $\lambda=10.6 \mu \mathrm{m}$. J. Appl. Phys. 1989, 66, 1326-1332.

18. Crane, K.C.A.; Garnsworthy, R.K.; Mathias, L.E.S. Ablation of Materials Subjected to Laser Radiation and High-Speed Gas Flows. J. Appl. Phys. 1980, 51, 5954-5961. [CrossRef]

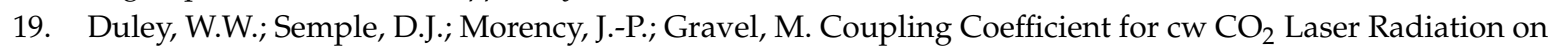
Stainless Steel. Opt. Laser Technol. 1979, 11,313-316. [CrossRef]

20. Miyamoto, I.; Maruo, H. The Mechanism of Laser Cutting. Weld World 1991, 29, 283-294. [CrossRef]

21. Arzuov, M.I.; Karasev, M.E.; Konov, V.I.; Kostin, V.V.; Metev, S.M.; Silenok, A.S.; Chapliev, N.I. Investigation of the Absorption Coefficient of Metal Targets Irradiated by Pulse-Periodic $\mathrm{CO}_{2}$ Laser Radiation in Air. Sov. J. Quantum Electron. 1978, 8, 892-897. [CrossRef]

22. Ursu, I.; Apostol, I.; Mihailescu, I.N.; Nistor, L.C.; Teodorescu, V.S.; Turcu, E.; Prokhorov, A.M.; Chapliev, N.I.; Konov, V.I.; Ralchenko, V.G.; et al. A Study of the Compounds which are Induced on the Metallic Target Surface under the Action of a Pulsed Laser Plasmatron. Appl. Phys. A 1982, 29, 209-212. [CrossRef]

23. Ursu, I.; Apostol, I.; Craciun, D.; Dinescu, M.; Mihailescu, I.N.; Nistor, L.; Popa, A.; Teodorescu, V.S.; Prokhorov, A.M.; Chapliev, N.I.; et al. On the Influence of Surface Condition on Air Plasma Formation near Metals Irradiated by Microsecond TEA CO 2 Laser Pulses. J. Phys. D Appl. Phys. 1984, 17, 709-720. [CrossRef]

24. Kwon, H.; Baek, W.-K.; Kim, M.-S.; Shin, W.-S.; Yoh, J.J. Temperature-Dependent Absorptance of Painted Aluminum, Stainless Steel 304, and Titanium for $1.07 \mu \mathrm{m}$ and $10.6 \mu \mathrm{m}$ Laser Beams. Opt. Lasers Eng. 2012, 50, 114-121. [CrossRef]

25. Bergström, D.; Powell, J.; Kaplan, A.F.H. The Absorptance of Steels to Nd:YLF and Nd:YAG Laser Light at Room Temperature. Appl. Surf. Sci. 2007, 253, 5017-5028. [CrossRef]

26. Willamowski, U.; Ristau, D.; Welsch, E. Measuring the Absolute Absorptance of Optical Laser Components. Appl. Opt. 1998, 37, 8362-8370. [CrossRef]

27. Key to Metals AG. Total Materia Database. Available online: https://www.totalmateria.com (accessed on 16 October 2018).

28. Hipp, D.; Mahrle, A.; Jäckel, S.; Beyer, E.; Leyens, C.; Füssel, U. Method for high Accuracy Measurements of Energy Coupling and Melting Efficiency Under Welding Conditions. J Laser Appl. 2018, 30, 32414. [CrossRef]

29. Bergström, D.; Powell, J.; Kaplan, A.F.H. Absorptance of Nonferrous Alloys to Nd:YLF and Nd:YAG Laser Light at Room Temperature. Appl. Opt. 2007, 46, 1290-1301. [CrossRef] [PubMed] 
30. Porneala, C.; Willis, D.A. Observation of Nanosecond Laser-Induced Phase Explosion in Aluminum. Appl. Phys. Lett. 2006, 89, 211121. [CrossRef]

31. Comins, N.R. The Optical Properties of Liquid Metals. Philos. Mag. 1972, 25, 817-831. [CrossRef]

32. Tran, T.Q.; Chinnappan, A.; Lee, J.K.Y.; Loc, N.H.; Tran, L.T.; Wang, G.; Kumar, V.V.; Jayathilaka, W.A.D.M.; Ji, D.; Doddamani, M.; et al. 3D Printing of Highly Pure Copper. Metals 2019, 9, 756. [CrossRef]

33. Jadhav, S.D.; Dadbakhsh, S.; Vleugels, J.; Hofkens, J.; van Puyvelde, P.; Yang, S.; Kruth, J.-P.; van Humbeeck, J.; Vanmeensel, K. Influence of Carbon Nanoparticle Addition (and Impurities) on Selective Laser Melting of Pure Copper. Materials (Basel) 2019, 12, 2469. [CrossRef] [PubMed]

34. Beyer, E. Schweissen mit Laser. Grundlagen; Springer: Heidelberg, Germany, 1995.

35. Cui, C.Y.; Cui, X.G.; Ren, X.D.; Qi, M.J.; Hu, J.D.; Wang, Y.M. Surface Oxidation Phenomenon and Mechanism of AISI 304 Stainless Steel Induced by Nd:YAG Pulsed Laser. Appl. Surf. Sci. 2014, 305, 817-824. [CrossRef]

36. Hones, P.; Diserens, M.; Lévy, F. Characterization of Sputter-Deposited Chromium Oxide Thin Films. Surf. Coat. Technol. 1999, 120-121, 277-283. [CrossRef]

37. Gulbransen, E.A.; Andrew, K.F. Oxidation Studies on 304 Stainless Steel. J. Electrochem. Soc. 1962, 109, 560-564. [CrossRef]

(C) 2019 by the authors. Licensee MDPI, Basel, Switzerland. This article is an open access article distributed under the terms and conditions of the Creative Commons Attribution (CC BY) license (http://creativecommons.org/licenses/by/4.0/). 